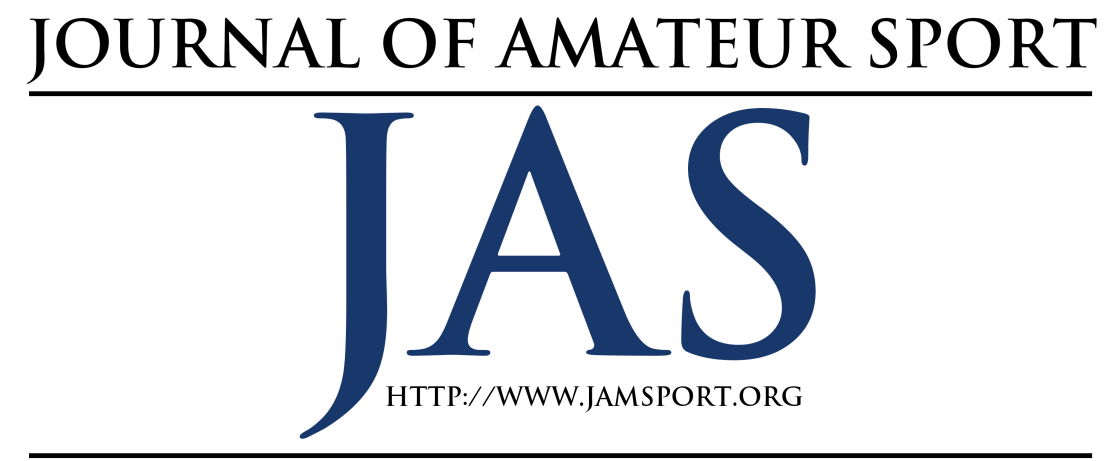

\title{
Investigating the negative fan behaviors of a branded collegiate basketball student section
}

\author{
Brian S. Gordon ${ }^{1} \quad$ Jeremy Arney ${ }^{2}$ \\ ${ }^{1}$ University of Kansas \\ ${ }^{2}$ University of Wisconsin - La Crosse
}

\begin{abstract}
Branded collegiate student sections (e.g., the Cameron Crazies at Duke University) have been identified as the most committed supporters of the team. The marketing benefits of these groups have been documented yet the potential negative consequences have gone unexplored in the literature. This study aimed to understand what types of behavior fans in this context engaged in, why they engaged in these actions, and attempts to link some of these observations to relevant theory on fan violence. A multiple method design was employed in order to obtain both breadth and depth of the phenomenon as well as for data triangulation. Ten members of a large, collegiate basketball fan group participated in in-depth, semi-structured interviews and extensive fieldwork of the fan group was conducted over the course of a season. Finally, 197 members of the same college basketball fan group responded to a survey questionnaire. The results of this study indicated there are negative consequences linked to the behavior of members of the branded student section. University officials should be aware of the potential danger of these branded student sections and strengthen relations and authority over these groups to minimize the likelihood of negative fan behavior.
\end{abstract}

\section{ccording to the National Summit on Civil Disturbances (2005), sporting events account for over $25 \%$ of}

convivial event disturbances on college campuses. Even more, previous research that has focused on fan violence has lacked a universally agreed-upon definition of the phenomenon (Spaaij, 2014). Negative sport

*This version of the article was revised to acknowledge this data was also used as part of an article by Rudd and Gordon (2010) on sportsmanship. 
fan behavior encompasses more than just physical acts of harm toward other fans and players as well. It has been welldocumented, and glorified under the auspice of "home advantage," that acts of verbal aggression directed at opposing players and fans are a common aspect of sporting events (Burgers, Beukeboom, Kelder, \& Peeters, 2014; Grove, Pickett, Jones, \& Dorsch 2012; Wann, Carlson, \& Schrader, 1999; Wann, Schrader, \& Carlson, 2000). Thus, the aim of this study is to use an immersive multiple methods approach to more holistically examine the construct of negative sport fan behavior.

The authors relied on a broader, more inclusive conceptualization of negative fan behavior to frame this inquiry. The conceptualization proposed by Branscombe and Wann (1992) that encompasses both aspects of negative fan behavior was used as a baseline definition in developing interview and observation guides. Branscombe and Wann (1992) viewed spectator aggression as, "the motive to harm another who does not wish to be treated in such a manner" (p. 1015). Further, we were drawn to Young's (2012) description of sports crowd violence whereas it was described as "acts of verbal or physical aggression (threatened or actual), perpetrated by partisan fans at, or away from, the sports arena that may result in injury to persons or damage to property" (p. 42). While this may sound simplistic, this definition emphasizes a more holistic approach to aggression and can be interpreted to include both physical and verbal instances of aggression.

In addition to spectator aggression, this study also wishes to expand on the social psychological notion of collective action. Numerous psychological theories have been applied to the group context to explain collective violence. Social identity theory (Tajfel \& Turner, 1979) explains how the group dimension installs itself in the minds of individuals and influences and shapes fan behavior. An individual's social identity is the self-perception that is derived from their membership within a particular group and this perception leads the individual to discriminate in favor of their group in comparison to a rival group (Tajfel \& Turner, 1986). Individuals have a strong desire to maintain a positive social identity as well as a high level of self-esteem and this is reflected in the types of comments fans make about behaviors by in-and out-group members (Burgers et.al, 2014; Wann, 1993). As Wright (2009) stated,

The psychological study of collective action has been dominated by an interest in determining when and why individuals will (and will not) engage in collective action...A group member engages in collective action any time she or he acts as a representative of the group and where the action is directed at improving the conditions of the group as a whole. (p. 860)

In all, the behaviors and actions of participants in this study were viewed 
through this broadly defined lens of aggression and collective action outcomes.

Before the relevant theory is discussed, it is imperative to understand the current climate surrounding fan violence. As an example, The National Collegiate Athletic Association (NCAA) has formed special committees, enacted legislation, and convened a summit of academicians and practitioners in 2003 to address this issue. Furthermore, many incidents of violence have been committed by fans in response to the outcome-win or loss_-of a sporting event. These incidents have caused considerable property damage, led to countless arrests, and taken innocent lives as a result.

Recently, Kansas State basketball fan Nathan Power was issued a summons to appear in court for a disorderly conduct charge after he rammed into University of Kansas player Jamari Traylor after a home upset win of the Jayhawks (KSN TV, 2015). Power apologized to KU admitting to letting "my emotions get the best of me in all of the chaos", and Kansas State University president Kirk Schulz sent out a letter to everyone on the campus reminding them of the importance of making a better impression of the "Wildcat Way" than what was nationally witnessed on television by thousands of viewers across the country (KSN TV, 2015). In addition, 31 people were arrested in close proximity to the University of Kentucky campus for disorderly conduct and public intoxication after mass rioting broke out in response to the Wildcats loss in the Final Four to the University of Wisconsin last spring. Police in riot gear fired pepper balls and employed a street sweeper to break up the crowd of over 1,500 fans who gathered to protest the stunning loss (The Associated Press, 2015). Finally, the University of Michigan's Athletic Director released an open letter urging fans to avoid "thoughtless comments" after a punting mistake cost Michigan the October 17, 2015, game against Michigan State (mmc-news.com, 2015).

As an indication of the importance of this issue, the NCAA has taken several steps to better understand fan violence and has also initiated policy in an effort to prevent future occurrences. In response to fan violence concerns, the NCAA has offered sportsmanship seminars at its annual convention. Additionally, it has proactively encouraged its respective institutions to draft uniform guidelines and standards regarding negative fan behavior. Finally, it has offered leadership conferences for student-athletes in an effort to set an example for younger fans ("NCAA President", 2006). At the conference level, steps have been taken to ensure fan safety in response to incidents of fan violence. In the Big Ten, the University of Wisconsin and University of Minnesota have increased security and installed immovable barriers that prevent students from storming the field. This is in response to an incident at the Madison campus that critically injured six students and sent 73 to the hospital. In 
accordance with NCAA recommendations, the University of Minnesota has installed collapsible field goal posts to prevent rowdy fans from tearing them down (Gruca, 2005). These administrative reactions illustrate some of the outcomes that negative fan behavior can have on sporting events. The consequences of fan violence and subsequent actions taken by the NCAA demonstrate the significance of this issue in intercollegiate athletics. Furthermore, it is essential to understand the theoretical explanations of fan violence in order to study the problem more thoroughly.

\section{Review of Literature Previous Fan Behavior Frameworks}

Prior studies of crowds at sporting events have highlighted numerous characteristics of the crowd composition that may contribute to the precipitation of fan violence. According to Simons and Taylor's (1992) Psychosocial Model of Fan Behavior, de-individuation - which is related to anonymity — can lead to an "abandonment of personal responsibility and a weakening of personal and social restraints that normally guard against socially unacceptable behavior" (p. 216). In the realm of a sport stadium, a feeling of anonymity can lead an individual to believe that his or her actions will not result in social or legal repercussions. However, the idea of anonymity has been challenged by research showing that people in crowds typically assemble with friends or family, and therefore, people who come in groups are more likely to act collectively than as anonymous individuals (McPhail, 1991; Schweingruber \& Wohlstein, 2005).

Nevertheless, previous research has shown that individuals tend to act differently in the confines of a group as opposed to normal circumstances (Branscombe \& Wann, 1992; Goldstein, 1989; Mann, 1979; Mustonen, Arms, \& Russell, 1996; Wann \& Dolan, 1994). There are many theories of collective behavior that attempt to explain how the various notions of "group-think" affect individuals who comprise these groups (Hart 1998; Janis 1972). For example, Contagion Theory, first introduced by French theorist Gustav Le Bon (1895), explains that behaviors and attitudes may be disseminated and unanimously accepted by a crowd and this creates a chain reaction of elevated arousal throughout the group as a whole. In essence, Le Bon asserted that emotions such as fear and hate are contagious in crowds because people experience a decline in personal responsibility and do things collectively that they would never do when acting alone. For example, an individual's arousal level may be raised by a precipitating event (bad call; taunts from rival fans) and this individual affects others within the group thus raising the arousal level of the group as a whole. Because of this, "crowd behavior is volatile and spontaneous" (Schweinberger \& Wohlstein, 2005, p. 144). Nonetheless, the persistent problem of relying upon Contagion Theory as an explanation of crowd behavior is the fact that there has 
never been a systematic study documenting the "collective mind."

Convergence Theory, which rejects Contagion Theory's explanation of the crowd transforming individual members, argues instead that people in a crowd act similarly because of their predispositionssimilar values and beliefs - that brought them together (McKee 1969; Simons and Taylor 1992). Due to these similarities, deviant group behavior may be accepted without critical thought by individuals and transferred indiscriminately throughout the entire group. However, McPhail (1991) has pointed out that similar to Contagion Theory, Convergence Theory assumes and attempts to explain crowd behavior by convincing the reader "that everyone in the crowd was continuously engaged in unanimous or mutually inclusive behaviorwhich is weak in supportive studies" (p. 71).

Unlike Contagion and Convergence Theories, Emergent Norm Theory emphasizes the importance of social norms in shaping crowd behavior. Drawing upon the Symbolic-Interactionist perspective of sociology, Turner and Killian (1972) asserted that crowds develop their own definition of a situation and establishes norms for behavior that fit the occasion. Emergent norms occur when people define a situation as highly unusual or see a longstanding situation in a new light. Sociologists using the Emergent Norm approach seek to determine how individuals within given collectivity develop an understanding of what is going on, how they construe these activities, and what types of norms are involved. For example, in a study of audience participation, Clayman (1993) found that members of an audience listening to a speech applaud promptly and independently but wait to coordinate their booing with others, indicating they do not wish to boo alone. In addition, according to Emergent Norm Theory, once a crowd reaches some agreement on the norms, the collectivity is supposed to adhere to them. If crowd members develop a norm that condones booing or verbally taunting others, they will proceed to cheer for those who conform and ridicule those who are unwilling to abide by the collectivity's new norms.

\section{Perception Control Theory}

The previous theoretical frameworks used to depict crowd disorders focus solely on the group's behavior, and alleged "mass consciousness" of the crowd. Whereas McPhail's (1994) perception control framework allows us to look at both levels (and units) of analysis via the theoretical concepts of outcome violence (group behavior) and intended violence (acts specific to an individual and/or instigating leaders of the group). Therefore, Perception Control Theory is a much more holistic and informative theoretical framework than the previous ones we briefly outlined in our literature review and offers an alternative "processual" explanation throughout. According to McPhail (1994), when violence occurs in riots and other 
gatherings, it may take one or more of several forms including vandalism, looting, arson and assault. Perception Control Theory suggests two ways in which individual or collective violence could develop.

Outcome Violence. The first, "outcome violence", occurs when an individual or group of individuals have a nonviolent goal such as getting together to throw a large party. The idea is that they will do anything to achieve this goal, including defying the authorities if the authorities attempt to squelch their party plans. When they encounter resistance or disturbance, they attempt to circumvent, overcome, oppose or eliminate that disturbance-but it frequently persists, as do their efforts to overcome the disturbance. In the ensuing struggle between disturbance and purposive resistance, the outcome is violent even though the original purposes were not.

Intended Violence. The second path, according to McPhail, is "intended violence", in which an individual's intentions are violent from the beginning and they match their perceptions of the situation to achieve this violent end. An example of this would be British soccer hooligans who go to games intent on beating someone or those who participate in celebratory riots and from the beginning have the objective of vandalizing and burning property. They act to make their perceptions match their goal of violatingintimidating, assaulting, injuring or killinganother human being. McPhail mentions the research of Dunning, Murphy and Williams (1986; 1988) who make a persuasive argument that these working class males grow up in families in which they witness physical violence, in which they are recipients of physical violence, indeed in which they are often coached in violence by parents, older siblings and by peers to become skilled in violent actions and to enjoy the successful practice of violence which the British often call "aggro."

Further, McPhail (1994) has explained the target of this aggression by stating:

Hooligans' targets are typically the supporters of rival football teams but can be anyone who talks or looks or acts "different." It is a matter of "we" versus "them" not unlike the stereotypical categorization of members of one racial, language, or religious community by members of another (McPhail, 1994, p. 23).

Furthermore, in his article concerning football violence, Finn (1994) has pointed to the "flow (or peak) experiences" of those fans that attend soccer games, as well as those who participate in hooligan activities outside of the venue. Reflecting on his own research, he stated, "in studies of optimal or peak experiences individuals reported their subjective experiences that the activity was rewarding in and of itself: they experienced 'flow'; they were at one with the action" (Finn, 1994, p. 106). In Finn's discussion of Scotland's soccer "casuals" (sharply dressed hooligans), the pursuit of the "carnivalesque" has led some supporters to 
abandon the game and its outcome, and focus more on creating their own flow (or peak) experiences (Finn, 1994). More recently, Cleland and Cashmore (2016) point out how modern technology has allowed for the creation of hooliganoperated websites that help "expand and facilitate informal and transitional networks by glorifying violence through either videos, pictures, or a narrative description of violent engagement...enhancing the adrenaline rush and emotional arousal experienced by the hooligans" (p. 132). This is similar to what other North American scholars (Eitzen, 1981; Lang, 1981; Lewis, 1972) have written referencing to sport taking place in a "carnival-like" atmosphere. Eitzen (1981) wrote, "festivals allow the individual to participate in relatively unstructured and spontaneous behaviors. At sporting events, spectators can deviate from society's norms (within reasonable limits) without penalty" (p. 401). Nonetheless, recent attacks on English football fans by well-organized ultra-violent Russian hooligans led to the possibility of penalizing both the English and Russian soccer federations with expulsion from the 2016 European Championships by UEFA because of their fan-based violence (Ough, Morgan, \& Criddle, 2016).

Additionally, the majority of studies regarding this topic have been conceptual in nature. Numerous theories and models have been proposed in an attempt to understand the complexity of fan violence. Additionally, in the realm of sport literature, many of the research endeavors have examined the relationship between a specific variable (i.e. team identification) and its impact on individual's likelihood to commit acts of aggression. However, the literature is nearly devoid of in-depth examinations of these groups to determine the extent to which the above-mentioned theoretical frameworks apply in this situation. Consequently, a qualitative inquiry in a specific sport context would fill this considerable gap in the literature. Therefore, the results of such a study could make a considerable contribution to a larger study of fan violence. This study is primarily focused on addressing the following question:

R1: What type of collective behaviors do participants in a student-led cheering section engage in and how do these observations relate to either intended or outcome violence as purported in Perception Control Theory?

\section{Methods}

This case study employed a multiple methods approach to examine fan behavior. According to Yin (2009), the case study is a most appropriate method to use when asking "how" and "why" research questions. Case studies are also advantageous to a qualitative researcher when they have the ability to directly observe contemporary events unfolding, and the ability to gain access to the actors immersed in such events (Yin, 2009). The Institutional Review Board at Author One's university granted approval for this study and the multiple methods of data collection. 
First, Author One acted as an observer as participant (Gold, 1958) of a branded student fan group at a major Southeastern university during six home men's basketball games. The purpose of the observation was both direct data collection and to inform the questions asked in the subsequent interviews and open-ended questionnaires. During observation, Author One noted both the presence and void (based on past literature) of behaviors and characteristics by means of field notes. The access garnered allowed for observations to occur at multiple locations within the arena, including directly within the group and from adjoining sections. These multiple

perspectives allowed for a more rich description of the orientation and behavior of the member students in the section. In fact, relying on a "triangulation" of research methods is an important foundation for when a researcher is staking their claims based on studying only one case (Yin, 2009). In all, the primary location of the observation was in the vicinity of the student group to allow for the verbal behavior to be documented.

The second method of data collection involved face-to-face interviews which were audio recorded with 10 members of the branded collegiate student group. The use of these ten respondents was deemed acceptable due to the small membership in the branded student cheering section and the achievement of data saturation. Data saturation is the point "where any further data collection will not provide any different information from what you already have, that is you are not learning anything new" (Gratton \& Jones, 2004, p. 153). To further this point, the authors could have interviewed more student fan group members yet deemed it unnecessary since interviewee responses were similar. Eight males and two females were interviewed, which included two freshman, two sophomores, four juniors, and two seniors. The protocol for the interviews was semistructured using an interview guide (Johnson \& Christensen, 2008) with questions derived from previous literature and the aforementioned observations (see Appendix A for interview protocol). With this approach, "the researcher adopts a flexible approach to data collection, and can alter the sequence of questions or probe for more information with subsidiary questions" (Gratton \& Jones, 2004, p. 141). As an example, one series of questions focused on the level of group solidarity that was present among student group members. Previous theories of collective behavior have suggested that the more members of a group identify with each other and feel a shared connection, the higher likelihood that group action directed towards an outgroup may be initiated. A second question line examined the explicit physical and verbal behaviors that were witnessed and initiated by group members. Additionally, questions were asked surrounding the organizational characteristics of the student section. In many cases, this information did not directly relate to their behaviors at 
games. Rather, the degree of organization is related to the strength of connection or level of "group think" that may be present among members.

The last method of data collection occurred through open-ended questionnaires emailed to the roughly 1,200student group member list ( $\mathrm{n}=198)$.

Prompts included, "Why did you choose to become a member of the [student fan group]?" and, "Please describe the types of cheering you do. What kinds of things do you say to the players and opposing team?" Additionally, descriptive survey questions were included gauging the respondents' frequency of attendance, interest in the team and sport, and general views on sportsmanship by both players and fans (the sportsmanship results can be found in Rudd \& Gordon, 2010).

\section{Data Analysis}

Authors One and Two transcribed the responses from the interviews and field notes. Open coding (Corbin \& Strauss, 2008) was employed where the utilization of a deductive, or using the established theory, approach was used to identify themes from the three data sources. First, both the authors independently coded responses and observations, based on the a priori themes used to develop the interview guide. Within the deductively identified groupings, emergent themes were proposed based on the responses and observations that differed from previous theory. When disagreements in coding appeared they were discussed between both of the authors until consensus was reached. According to Miles and Huberman (1994):

Codes are the mechanisms used to retrieve and organize these chunks from data gathered, say from transcribed notes of an interview. The organization of chunks entails some system for categorizing the various chunks, so the researcher can quickly find, pull out, and cluster the segments relating to a particular hypothesis and/or construct relevant to the study. Clustering and displaying the condensed chunks sets the stage for drawing conclusions ( $p$. 57).

In regards to reliability and validity, the five verification strategies posited by Morse, Barrett, Mayan, Olson, and Spiers (2002) were utilized: (1) methodological coherence, (2) appropriate sample population, (3) collecting and analyzing concurrently, (4) thinking theoretically, and (5) theory development. In the following results section, the reader will find summarized results paired with verbatim responses to account for both the voice of the researchers and participants. This is in response to Corbin and Strauss's (2008) assertion that, "though we break data apart, and identify concepts to stand for the data, we also have to put it back together again by relating those concepts" (p. 198).

\section{Results}

Based on an analysis of interview transcriptions, email communication among group members, field notes constructed 
from six observations, and open-ended survey responses, the results were constructed and are presented in this section. The results of the open coding process generally fell into one of six categories: (1) intent of fan behavior, (2) group communication among fan group members and "cheer sheets" as evidence of intended violence, (3) dehumanizing the opponent, (4) "blasting" referees/rival players/rival fans as evidence of outcome violence, (5) the importance of perceived anonymity, and (6) the important role leaders play in organizing and initiating negative fan behavior. Results are organized below according to theme. Representative quotes are presented in verbatim form.

\section{Evidence of Intended Violence}

The most salient theme from an examination of interview transcriptions, email communication among group members and an examination of "cheer sheets" was the pre-disposition of many group members to engage in acts of nonphysical (verbal) violence. They came across clearly through an examination of group member emails as well as interview responses. The student fan group has a designated researcher who is responsible for digging up "dirt" on opposing players and disseminating this information to fan group members for the intent of using it against him or her during the game. The following email communication from the fan group leaders to the members clearly illustrates this:
Many of you know [student fan group researcher name], if we do a chant or a sign about a player on the other team, it is often due to [researcher name's] stellar research. For the game tomorrow, [opposing player name] is returning from injury. [Researcher name] has been posing as a groupie of [opposing player name] and has pretended to be a girl. He has gotten some good information out of [opposing player name] and we can use this information against [opposing player name] at the game tomorrow. The "dirt" gathered about opposing players is compiled by the student group's researcher and put into cheer sheets that are disseminated to the entire membership via email and at the event site as well. It was clear no topic was off limits in regards to the information utilized against opposing players, and star players are typically the targets. A member of the student fan group shed some light on what information is collected and used against opposing players:

Some members were talking to [opposing player name] of [opposing school]. His father was [opposing player's father name] who was a former MLB player and drug addict. The people that run it [student fan group] were calling him "crack baby" because of his father's past.....another time, we were playing [school name] and the members focused on a [school name] player because he was Cuban....also, the girls team too... There is a [student 
fan group name] for women's basketball too. Some people will make comments about the opposing team looking like monsters, beasts, and even lesbians.

Beyond the advanced communication to group members and the construction of cheer sheets, many student fan group members also indicated that the purpose of the fan group was to "get inside the opponent's head" as well as provide a hostile environment and home court advantage for the team. They provided specific examples of games where they felt like their relentless heckling and taunting impacted the final score, illustrating the presence of a "collective efficacy" (Bandura, 2000). Further, they provided examples of specific players that incurred their wrath (usually a star player) and suffered from a poor performance as a result. This indicates that these members joined the group with the expressed intent of engaging in negative fan behavior and view the group as the conduit to achieve this goal. Student group leadership furthered this purpose through group emails and cheer sheets that perpetuated this notion that the group had an impact on the outcome and this outcome should be achieved by any means necessary. To further reinforce the role that the fan group plays, the university itself branded this group "the $6^{\text {th }}$ man" and recognized them before every home game.

\section{Evidence of Outcome Violence}

From an examination of the interview transcripts as well as extensive fieldwork, fan group members showed a proclivity for "acting in the moment" in response to external stimuli in the environment (i.e. bad call by a referee, taunting by opposing fans, dehumanizing an opposing player who is having success in the game) or a "precipitating event" (Smelser, 1963). For example, fan group members may have flocked to the arena with the intentions of simply enjoying the game, supporting their team in a positive manner and commiserating with their fellow fan group members. Further, many respondents indicated very benign intentions (i.e. support the team, get better seats, meet new people, get a free t-shirt, fun) for joining the student fan group as well as defining the overall purpose of the group. However, their behavior turned abusive (verbally) in response to occurrences at the event site. This was a reoccurring theme in the interviews as well as the open-ended survey responses such as:

I've crossed the line a couple times. Just get caught up in the emotion of it, so its just like I yell something but I think like, this is really irritating to me, I say something to the effect of you are a fucking idiot, get the hell out of here, get back to the locker room.... try to keep myself composed I think I just get too caught up in what is going on during the game and in the stands...... this goes back to what I said earlier about the mob mentality, the us versus them and we need to beat them. 
You know, I get caught up in it sometimes.

Another indication of outcome violence came from the open-ended survey responses. The degree to which fan group members discussed the referees, opposing players, and rival fans as specific targets of their taunting and heckling was apparent. A good representation of their dehumanizing out-group members can be discerned from these statements:

There are time we will call the other opposing fans faggots, other times we will criticize the refs, say horrible things like "FU" or I hope you die, stuff like that...People will threaten the refs like I will be waiting for you after the game....things like that. It is part of the game.

It happens all the time, I mean there is the "FU" chant, the "bullshit" chant and don't forget about the refs... sometimes they say things about their mothers, its usually who they take their anger out on.

It is important to note the context of some of these comments as well. Although in some cases fan group members intended to target these individuals going into the game (which would reinforce the tenets of intended violence), there was a theme that emerged regarding how their behavior was in response to the actions of one of the aforementioned groups. For example, numerous fan group members described how they taunted and threatened rival fans at the event site as a retaliatory behavior to comments made earlier or in response to what was happening on the court. Further, to reinforce the lack of intent in regards to some of this negative fan behavior, some of the fan group members had initially indicated that they did not engage in negative fan behavior or verbal violence. However, when pressed in the interview or provided a situation, some conceded that they would "blast" an out-group in response to a "trigger" in the environment.

Finally, in a related fashion, fan group members also indicated they were engaging in this negative behavior due to their participation in this group context. This was best illustrated with the following comment: I probably would not do any of it if I did not have any other people around me doing it. I don't want to be singled out, that is just not my personality, I don't think and if there is no one else around me, I would probably not cheer or yell at the refs and opposing players....I would probably fall back and be a pretty terrible fan (if not for the group membership).

There were many similar comments in this vein. There seemed to be a faction of group members who indicated that they would not engage in the yelling or taunting if not for their membership in the group and the context overall. So, in some respects, it is not just a precipitating event on the court (bad call or opposing star players' actions) or in the stands (response to rival fans) that leads to outcome violence by some of the fan group members but a response among 
the individual group member to the reaction of the group they reside in as a whole.

\section{Evidence of Leaders and Followers}

Through fieldwork, group email communication, and interviews, it was evident that the student fan group under examination had a hierarchical structure that took various forms depending on the context. The "formal" structure of the group included board members who have clearly defined roles, regular meetings, and were active in organizing and managing the over 1,200 fan group members. Beyond the day-to-day operations of the group, the presence of a leadership structure impacted the behavior of the overall group as well. As previously noted, one member had the role of "researcher" for the group. The researcher dug up information about opposing players that would be used against them at the live event. During interviews and observations, the "dirt" that was uncovered included the names of family members, significant others, any previous legal infractions, or even the racial/ethnic background. Further, the researcher would try to uncover campus contact information or cell phone numbers in an effort to harass the player daily through phone calls to their dormitory room or personal phone. Finally, in some cases, the researcher would be an "imposter" (or a groupie as the researcher called it) on social media and attempt to extract information through this rouse. The most common approach was for the researcher to pretend to be a female admirer. All of this effort culminated in the construction of personal information to use against the star player on game day and it was deliberately collected and disseminated to group members by the leadership of the group.

Another theme regarding the presence of leaders and followers was at the event itself. Typically, the most ardent supporters of the team and of the group would be located in the front row, centered for all group members to see on event day. It was also likely that they would be dressed in eclectic outfits as a way to further differentiate themselves from the group as well as to be highly identifiable. Often, they would be directing uniform chants and cheers (some very benign and support those that were offensive and threatening) as mentioned here:

Usually, my friend, [friend's name] who stands next to me will start them....he starts a lot of them and another kid, [kid's name] will do that as well; they're usually the instigators that everyone else follow... but that's kind of the way it works, we don't do any like random people to start it.

Not only does the group context have an impact on each individual member of the fan group but also the results here suggest that some individual group members play a significant role in the behavior of the overall group. A number of group members discussed how their fan behavior at the event was significantly impacted by their membership in the group. This theme takes 
it even a step further in that it is not only the group that instills itself in the individual but also individuals within the group who help drive and dictate the overall group behavior.

\section{Concept of Anonymity}

The idea that student fan group members are "anonymous" among the throng of people in their section did not manifest itself in the manner as previous research on collective behavior would suggest. Many of the student fan group members know each other, travel in packs to the facility for the game, and sit by one another. Further, from interviews and the open-ended questionnaires, meeting new people and building lasting social relationships was considered the main benefit of joining the student fan group by a lion's share of the respondents. Therefore, it can be deduced that it is likely that those sitting in the fan group section are familiar with each other and more than likely, know each other and are friends. These

observations contradict the traditional notion of "anonymity" or the "anonymous" crowd.

However, the concept of anonymity manifested itself through a different mechanism. Student fan group members indicated that they could verbally berate or even threaten out-group members (opposing players, rival fans, referees) without the fear of negative reprisal from the out-group members as well as from event personnel. A recurring observation from student fan group members was that nobody from the fan group section had ever been ejected from the facility for negative fan behavior. This fueled the belief that individuals could blend into the crowd and not be singled out by the aforementioned groups. While not anonymous to each other, they were in a sense anonymous to the groups that they were "blasting". This is best evidence by the following observation:

Yeah definitely...the power of numbers. If you say something and all these guys have your back, you feel like you can say anything to a six ten guy, 295 pound dude, jacked as can be...if we are all saying the same thing, its not like he will single one person out, you feel like there is nothing he can do about it. It's not like you have to worry about the guy waiting in the parking lot for you after the game.

There is the notion that around 1,200 fans have your back and emboldens individuals to act in a manner that they normally would not. The second part of the quote really hammers home the way anonymity manifested itself in this setting. As previously mentioned, it is not as if the crowd members are anonymous actors amongst each other. However, the crowd members feel a level of anonymity in regards to the out-groups that they are "blasting" and event/security personnel who may punish them for their acts of verbal violence and threats.

Beyond the lack of fear of negative reprisal, another anonymity-related theme 
dealt with how the group behavior or group "think" influences the individual actor. Some respondents indicated that they were willing to engage in behavior in the group context that they would not normally do if they attended the game, not representing and commiserating with members of the student fan group. That can best be illustrated here:

Just being in the group, everyone is yelling and you do not want to be the only one not yelling or being involved in it if I tried to think about it. I wouldn't be at a game by myself just standing on the side yelling this stuff.

This ties into the idea that student fan group members in this context have lost their sense of independence, their sense of self, and have surrendered themselves to the actions of the crowd, open to the guided behavior of the overall group.

\section{Discussion}

The following section includes a discussion of how the results in this context relate to previous work on fan violence as well as how it contributes independently to the existing literature. Implications for sport administrators from the results of this study are included as well as practical suggestions for how to curb negative fan violence in similar contexts is provided. Finally, a discussion of future research avenues based on the findings is included.

From extensive fieldwork and a thorough examination of the interview data, the most prevalent and reoccurring theme centered on the tenets of perception control theory. There has been a considerable debate in the field of sociology (more specifically, in the area of collective behavior) about the nature of convivial gatherings, urban riots, and social movements. One common conception is collective behavior participants were "transformed by the crowd into irrational pawns of suggestion and contagion...that they were riffraff of society or otherwise perverted personalities predisposed to participate in social movements" (McPhail, 1994, p. 13). Further, collective crowd behavior has been argued to be "spontaneous, unorganized, undirected, and unjustifiable" (Simons \& Taylor, 1992, p. 212). Alternatively, our results suggest that collective behavior falls within the other common discourse. Collective behavior is characterized by rational actors who are goal-oriented, participants who are not driven by economic deprivation, and organized through a complex social network and coordinated communication where participants could be recruited with a purpose (McPhail, 1994).

There were many markers of intended violence found among student fan group members. First, this organization of about 1,200 students had a formal board and leadership structure that disseminated information regularly to its members. This information included "cheer" sheets that provided instructions for collective action among its members at the event site. Further, these sheets contained in-depth 
information, or "dirt," about opposing players and coaches. The "dirt" included mother and father's names, girlfriends' names, details of arrest records, campus contact information, and even a famous father of one athlete who had a recurring drug problem. This information was compiled, disseminated, and used against the target to "rattle" them on and around event day. It went so far as to even identify where opposing players' parents were sitting and direct coordinated comments at the parents during the event. These observations are evidence of the, "intrapersonal processes of individual and collective actions as well as the complex structures of how action is built, elaborated, and transformed" (McPhail, 1994, p. 16). Further, it is an apt illustration of Harrison's (1974) observation that certain individuals attend sporting events for the express reason of acting out their aggressive tendencies.

There was also ample evidence to suggest that student fan group members also engaged in acts of verbal violence in reaction to environmental stimuli. There were several instances where respondents indicated that they joined the group with a nonviolent goal in mind (support the team, make friends, good seats, student section tshirt). While they began with an innocent goal, they ended engaging in negative fan behavior at the event site in reaction to a triggering event (opposing player has success, referee makes a bad call, rival fans become a threat). These are ideal examples of what McPhail (1994) would categorize as outcome violence. Stated differently, "In the ensuing struggle between disturbance and purposive resistance, the outcome is violent even though the original purpose were not" (McPhail, 1994, p. 22). The fieldwork and interviews also reinforced the fact that student group members felt a connection with other group members and shared a "oneness" in with the group in some instances. Therefore, to understand outcome violence, it is important to realize that when the group feels a threat to their own collective self-concept, the reaction typically is to derogate the target out-group and to reinforce their own self-concept (Lott \& Lott, 1965; McPhail, 1994; Tajfel \& Turner, 1979). Strong support for the processual approach to collective behavior was evidenced here as well as the central role of perception control among student fan group members.

Two related and recurring themes in previous psychosocial literature are the importance of a leader in directing and driving collective behavior as well as the "mobilization of participants" as stated by Smelser (1963). In this particular student fan group, there were a variety of "protagonists" that directed and stoked collective behavior, both at the event site as well as through communication channels. Through observation, it was evident that one or two student fan group members acted as leaders that were directing crowd behavior at the event site. Whether it was positive, group chants to support the team 
and implore for better performance or negative chants (such as bullshit or "FU"), the same group members directed the cheering at all six observations. Even more interesting was the leadership and direction that occurred before the event. Especially during high profile and rivalry games, there was a structured, concerted effort to construct negative information about the opponent for utilization of game day. Not only was it accepted by the official board (leadership) for the student fan group but it was also praised repeatedly from an examination of group communication as well as during the interviews. The conduct of the "group researcher" was a tale told over and over again by respondents. By means of social media, official university records, and police reports among other sources, personal information of opposing players was compiled and used as a tool to humiliate the student-athlete on a regular basis, not only on game day but also during the week of the game. All of this behavior sanctioned and praised by the group's leadership. The impact of various leaders on the collective behavior of the group cannot be understated in this context.

The results also suggest very strong support for the concept of "deindividuation", the idea that when you are in the presence of a group with a strong connection, individuals may be susceptible to abandoning personal responsibility as well as losing a sense of self and social restraint (Simons \& Taylor, 1992). While it is important to note that fan group members did not feel a sense of anonymity within the section that they sat in, it was evident that they felt emboldened to threaten opposing players or fans and antagonize the referees due to the false confidence they obtained through being in a large group setting. This manifested itself in two ways. First, there was a lack of fear that they would be confronted physically by the out-group member that they were threatening due to this strength in numbers. Next, they did not feel as though they would be identified or singled out of the crowd if they did engage in negative behavior. This was reinforced by the fact that no group member during that season was removed from the premises for inappropriate or threatening behavior. The sense that the crowd would have their back physically and the fact that they could blend in clearly led to more aggressive behavior on behalf of the individual attendee.

Another theoretical lens through which the results can be viewed is by means of emergent norms theory (Turner \& Killian, 1972). As Turner and Killian (1972) contend:

Some shared redefinition of right and wrong in a situation supplies the justification and coordinates the action in collective behavior. People do what they would not otherwise have done when they participate collectively, when they riot, when they engage in civic disobedience, or when they launch terrorist campaigns, because they find social support for that and what they 
are doing is the right thing to do in the situation. (p. 12)

This notion that "right and wrong" behavior is not only coordinated by the group but also is accepted (not by all group members in this context) was evident in the interviews as well as observations.

Respondents indicated that their behavior mirrored that of their peers in the group so as to not stand out as an outlier or to feel as part of a whole. Further, many respondents were willing to commit acts of negative fan behavior due to the fact that they were in the group context and it was an expectation of what you should do as a member of the group. Interestingly, some respondents indicated that some of the behavior of the group crossed the line of right and wrong yet they were able to rationalize it because it was "part of the game" or necessary to achieve the group's overall purpose which was to "get inside the opponent's head" or create a hostile environment.

As important as it is to detail what the authors found, there is much value in understanding what we did not observe or find was present. First, in this context, the notion of explaining our results through the lens of convergence theory (McKee, 1969) was highly unlikely. From the interviews and open-ended questionnaire, it was evident that student fan group members joined for a variety of reasons. Further, and more importantly, when asked about the purpose of the fan group, there was a wide variation of responses. This notion that "birds of a feather flock together" was clearly not demonstrated in this context. While their motives for group membership, attending the events, and the overall purpose of the fan group varied, they still engaged in many of the same negative (and positive) fan behaviors. Hence, McPhail (1991) has pointed out that similar to Contagion Theory, Convergence Theory assumes and attempts to explain crowd behavior by convincing the reader "that everyone in the crowd was continuously engaged in unanimous or mutually inclusive behaviorwhich is weak in supportive studies" (p.71). We tend to agree with this assertion based on the results of this study.

Beyond the lack of support for Convergence and Contagion Theories, we did not find support for a well-established "situational" characteristic that has garnered much support from previous conceptual research as well as the popular press. The role of alcohol in influencing crowd behavior in this particular setting was significantly minimized based on interviews and extensive fieldwork. Interestingly, because the facility was off-campus, alcohol was sold on the premises yet there was nothing to suggest that alcohol played a major role in influencing fan group behavior. Understandably so, this might have been a contextual finding and further work needs to be done to understand the impact of alcohol on negative fan behavior.

\section{Limitations and Directions for Future} Research

There were a few limitations of the current study. First, this study only 
examined negative fan behavior among members of one collegiate branded student section. Further, utilizing case study methodology, the generalizability of our results to a broader population may be limited. As noted by Yin (2009), critics often question the representativeness of a single case study to a particular theory or conceptual framework. These critics are implicitly contrasting the context of a single case study to survey research where a sample is intended to generalize to a broader population. As Yin (2009) points out, "this analogy to samples and universes is incorrect when dealing with case studies...survey research relies on statistical generalization whereas case studies rely on analytic generalization" (p. 43). With analytic generalization, the investigator is looking to generalize a specific set of results to some broader theory. Second, this particular sample comes from a school that is not regarded as a traditional "basketball school". In fact, the basketball program is positioned in the shadow of an internationally regarded football program. It stands to reason that the results could be different when looking at a "basketball powerhouse" where their student fan group may be more organized, more avid, and the game environment may be more emotionally charged. Finally, the exploratory nature of our study provides prefatory findings that should be viewed in context rather than drawing conclusive denouements.

From the fieldwork and interviews, a number of avenues for future research were evident. First, as Simons and Taylor (1992) described in their psychosocial model of fan violence, there are a number of "situational" characteristics that warrant further attention. For example, the presence of a rivalry game as well as a high profile matchup (in this case, nationally televised against a historically strong opponent and/or highly ranked opponent) should be examined further in regards to how it influences negative fan behavior. The degree to which intended violence was present was more likely during high profile matchups or rivalry games. Specifically, it was clear that the "cheer" sheets contained much more "dirt" for games of this nature. Further, the vulgarity and use of dehumanization was much more prevalent in this context. Finally, while the use of alcohol was not a prevalent factor in this context (as evidenced by the interviews, observations, and survey questionnaire) scholars such as Ostrowsky (2014) and Scholes-Balog, Hemphill, Kremer, and Toumbourou (2016) have posited the importance of examining this situational factor and its role in spurring negative fan behavior.

There is a very rich knowledge base regarding the impact of team identification on the likelihood to engage in a range of negative fan behavior (see Wann et al., 2005 for an extensive literature review on this topic). While this area is well developed, the impact of fan community identification (Yoshida, Gordon, Heere, \& James, 2015) on the likelihood to engage in a range of 
negative fan behavior deserves further consideration. A very strong undercurrent of support for this relationship was uncovered in the results of this study. Fan group members indicated a connection to other members, a "consciousness of kind" (Muniz \& O'Guinn, 2001) due to the fact that they shared membership in the same group, wore the same apparel to games, believed they had similar goals, and were on the same email mailing list. Respondents indicated that they were more likely to engage in negative fan behavior due to the "backing" of other group members as well as the perceived social pressure placed upon them by other group members at the event site. Further, this feeling of group solidarity can be amplified when a threat (perceived or real) to the groups' goals or objectives is identified (Lott \& Lott, 1965). The results indicated that this "threat" might come from opposing star players, referees, or rival fans. While the sport marketing literature has viewed fan community identification through a positive lens in regards to the benefits to the organization, it stands to reason based on the results that this type of identification may have a "dark side".

Finally, in response to Wakefield and Wann's (2006) call for more research into individual factors, the findings here do pose some interesting avenues that need further examination. For instance, what makes some individuals more prone to engage in intended violence than others? Further, why do some feel that hostile and/or instrumental aggression by fans towards an out-group is "part of the game"? Essentially, how are these fans different from a psychosocial standpoint? Wakefield and Wann (2006) in response to that call examined fan violence from the perspective of the individual instead of the group explanation. Their results suggest that social identity theory and team identification may not be adequate explanations for the occurrences of fan violence in North America. Instead, Wakefield and Wann (2006) posited that "identification with the team is not the differentiating factor predicting anti-social behavior......anti-social behavior seems to be a characteristic or pattern of behavior of the individual dysfunctional fan" (p. 179). For example, the issue of fan violence has really only been examined from the male perspective. Hooligan scholars have mainly focused on the disruptive behavior of young adult males between the ages of 18-25, framing this behavior as young men acting out their male-specific "aggro" tendencies (Dunning, Murphy, \& Williams, 1986; 1988; Finn, 1994; McPhail, 1994). Studies in North America have largely focused on male sport fans thus a significant gap exists in the literature regarding how (or if) this applies to female fans. Taken as a whole, there is much more that we do not know about why fans engage in negative behavior than what previous literature tells us. Thus, this area of research would benefit from a revitalization of examination as well as more empirical work where researchers are looking at the behavior as it unfolds in the native context. 


\section{Conclusions}

The sport marketing literature as well as most popular press articles considers enhancing fans' identification toward the team a positive endeavor for sport organizations. Specifically, the construction of branded, student-led cheering sections has long been identified as the most committed and rabid supporters of the team. Most of these groups can be distinguished by a catchy nickname and matching apparel. Universities have attempted to capitalize on these groups through coordinated marketing activities such as selling apparel with the group's brand name on it ("Schools Cheer New Branding Effort”, 2007). These activities have added a new revenue stream for the university as well as strengthening the ties between fans and the university. The benefits these groups bring to the university have been well documented and some of the groups have become recognized student organizations on their respective campuses.

However, the potential negative consequences due to the formation of these groups have gone largely unexplored in the literature. As the results of this study indicate, the formation of these groups brings together a collection of passionate fans that share a mutual connection through group membership. Furthermore, these individuals are grouped together in the same section of the arena in close proximity of one another and have a feeling of anonymity as well as the lack of fear of negative reprisal. Finally, they are armed with "dirt" on opposing players that they will use against them when the game commences and are directed by leaders who have the intent of creating a "hostile" environment. When these elements are combined, the results can lead to an increase in physiological arousal (as well as frustration) as well as the proclivity for outgroup derogation (Branscombe \& Wann, 1992). Given the characteristics of the student-led cheering section, if a precipitating event (Smelser, 1963) was to occur (such as a negative call or negative outcome), the chance of negative fan behavior among this group might be more likely.

As a result, sport administrators need to be armed with this knowledge when these groups are present on their campus and attend athletic events. They should consider having direct oversight over the group as well as access to the communication they disseminate. Some universities are doing this by designating these student fan groups as recognized student organizations (RSO's) or delegating the marketing department personnel to have direct oversight over the group. Either way, these student fan groups should not be left to their own devices and allowed to operate without proper oversight including from game day personnel at the event site. 


\section{References}

A summit on best practices in responding to developing and ongoing civil disturbances in college communities (2005, November 10). Retrieved December 2, 2007 , from

www.dps.iastate.edu/nspcd/index.ht $\underline{\mathrm{ml}}$

Bandura, A. (2000). Exercise of human agency through collective efficacy. Current Directions in Psychological Science, 9(3), 75-78.

Branscombe, N.R., \& Wann, D.L. (1992). Role of identification with a group, arousal, categorization processes, and self-esteem in sports spectator aggression. Human Relations, 45(10), 1013-1029.

Burgers, C., Beukeboom, C.J., Kelder, M. \& Peeters, M.M.E. (2015). How sports fans forge intergroup competition through language: The case for verbal irony. Human Communication Research, 41, 435-457.

Clayman, S.E.(1993). Booing: The anatomy of a disaffiliative response, American Sociological Review, 58 (1): 110-131.

Cleland, J. \& Cashmore, E. (2016). Football fans' views of violence in British football: Evidence of a sanitized and gentrified culture. Journal of Sport and Social Issues, 40(2), 124-142.

Corbin, J. \& Strauss, A. (2008). Basics of qualitative research: Techniques and procedures for developing grounded theory. $\left(3^{\text {rd }}\right.$ Ed.) Thousand Oaks, CA.: Sage.
Dunning, E., Murphy, P., \& Williams, J. (1986). Spectator violence at football matches. British Journal of Sociology, 37, 221-244.

Dunning, E., Murphy, P., \& Williams, J. (1988). The roots of football hooliganism: An historical and sociological study. London, England: Routledge \& Kegan Paul.

Eitzen, S. D. (1981). Sport And Deviance. In George Sage and Gunther Luschen (Eds.), Handbook of Social Science of Sport. Champaign, IL: Stipes Publishing Company.

Finn, G. (1994). Football Violence: A societal psychological perspective. In Giulianotti, R., Bonney, N., and Hepworth M. (Eds.), Football, Violence, and Social Identity. New York: Routledge.

Gold, R. L. (1958). Roles in sociological field observations. Social forces, 217 223.

Goldstein, J.H. (1989). Violence in sports. In J.H. Goldstein (Ed.), Sports, games, and play: Social and psychological viewpoints (pp. 279-297) (2 $2^{\text {nd }}$ ed.) Hillsdale, NJ: Lawrence Erlbaum Associates.

Gratton, C., \& Jones, I. (2004). Research methods for sport studies. New York: Routledge.

Grove, S.J., Pickett, G.M., Jones, S.A. \& Dorsch, M.J. (2012). Spectator rage as the dark side of engaging sport fans: Implications for services 
marketers. Journal of Service Research, 15(1), 3-20.

Gruca, T. (2005, October 24). NCAA looks at collapsible goal posts. Retrieved December 2, 2007, from http://wcco.com/topstories/goal.po sts.football.2.352267.html

Harrison, P. (1974). Soccer's tribal wars. New Society, 29, 602-604.

Hart, P. (1998). Preventing groupthink revisited: Evaluating and reforming groups in government. Organizational Behavior and Human Decision Processes, 73(2/3), 306-326.

Janis, I.L. (1972). Victims of groupthink: a psychological study of foreign-policy decisions and fiascoes. Oxford, England:

Houghton Mifflin.

Johnson, B., \& Christensen, L. (2008). Educational research. Thousand Oaks, CA: Sage.

KSN Television. (2015, February 25). KState police announce action for student who bumped KU's Jamari Traylor. KSN Television. Retrieved from

http://ksn.com/2015/02/25/kstate-police-announce-action-forstudent-who-bumped-kus-jamaritraylor/.

Lang, G. E. (1981). Riotous outbursts at sports events. In George Sage and Gunther Luschen (Eds.), Handbook of Social Science of Sport. Champaign, IL: Stipes Publishing Company.
Le Bon, G. (1960, originally published in 1895). The Crowd: A Study of the Popular Mind. New York: Viking. Lewis, J.M. (1972). A study of the Kent State incident using Smelser's theory of collective behavior." Sociological Inquiry, 42 (2): 87-96.

Lott, A.J., \& Lott, B.E. (1965). Group cohesiveness and interpersonal attraction: A review of relationships with antecedents and consequence variables. Psychological Bulletin, 64, 259309.

Mann, L. (1979). Sports crowds viewed from the perspective of collective behavior. In J.H. Goldstein (Ed.), Sports, games, and play: Social \& psychological viewpoints (pp.337-368) $\left(2^{\text {nd }}\right.$ ed.). Hillsdale, NJ: Lawrence Erlbaum Associates.

McPhail, C. (1991). The myth of the madding crowd. New York, NY: Aldine De Gruyter Publishing Company. McPhail, C. (1994). The Dark Side of Purpose: Individual and Collective Violence in Riots. Sociological Quarterly, 35(1):1-32.

Miles, M.B., \& Huberman, A.M. (1994). Qualitative data analysis: An expanded sourcebook. New York, NY: Sage Publications.

mmc-news.com (2015, October 17). Michigan punter's social media threats prompt response by AD. Retrieved from http://mmcnews.com/news-michigan-punter- 
and-8217;s-social-media-threatsprompt-response-by-ad-274937.dbv. Morse, J. M., Barrett, M., Mayan, M., Olson, K., \& Spiers, J. (2002). Verification strategies for establishing reliability and validity in qualitative research. International Journal of Qualitative Methods, 1(2), 1-19.

Muñiz, A.M., \& O'Guinn, T.C. (2001). Brand community. Journal of Consumer Research, 27(4), 412-432.

Mustonen, A., Arms, R.L., \& Russell, G.W. (1996). Predictors of sports spectators' proclivity for riotous behavior in Finland and Canada. Personal Individual Differences, 21(4), 519-525.

NCAA president: instilling sportsmanship rests with schools. (2006, October 20). Retrieved December 2, 2007, from http://www.cstv.com/sports/mfootbl/stories/102006adb.html

Ostrowsky, M.K. (2014). The social psychology of alcohol use and violent behavior among sport spectators. Aggression and Violent Behavior, 19, 303310.

Ough, T., Morgan, T., \& Criddle, C. (2016). Euro 2016: UEFA threatens to disqualify England and Russia amid German and Ukraine violence in Lille. Retrieved June 13, 2016 from http://www.telegraph.co.uk/football /2016/06/12/euro-2016-uefainvestigate-violence-betweenengland-and-russia-f/.
Rudd, A., \& Gordon, B.S. (2010). An exploratory investigation of sportsmanship attitudes among college student basketball fans. Journal of Sport Behavior, 33(4), 466-488.

Scholes-Balog, K.E., Hemphill, S.A., Kremer, P.J., \& Toumbourou, J.W. (2016). Relationships between sport participation, problem alcohol use, and violence: A longitudinal study of young adults in Australia. Journal of Interpersonal Violence, 31(8), 1501-1530.

Schweingruber, D., \& Wohlstein, R.T. (2005). The madding crowd goes to school: Myths about crowds in introductory sociology textbooks. Teaching Sociology, 33(2), 136-153.

Simons, Y., \& Taylor, J. (1992). A psychosocial model of fan violence in sports. International Journal of Sports Psychology, 23, 207-226.

Smelser, N.J. (1963). Theory of collective behavior. New York: Free Press.

Spaaij, R. (2014). Sports crowd violence: An interdisciplinary synthesis. Aggression and Violent Behavior, 19, 146-155.

Tajfel, H. and Turner, J. C. (1986). The social identity theory of inter-group behavior. In S. Worchel and L. W. Austin (eds.), Psychology of Intergroup Relations. Chicago: Nelson-Hall

Tajfel, H., \& Turner, J.C. (1979). An integrative theory of intergroup conflict. In W.G. Austin \& S. Worchel (Eds.), The social psychology of intergroup relations. Monterey, CA: Brooks/Cole. 
The Associated Press (2015). Kentucky fans riot, light fires after Final Four loss to Wisconsin. Retrieved from http://www.nydailynews.com/sports /college/kentucky-fans-riot-finalloss-wisconsin-article-1.2174167.

Turner, R.H., \& Killian, L.M. (1972). The field of collective behavior. ( $2^{\text {nd }} \mathrm{Ed}$.) Englewood Cliffs, New Jersey: The Free Press.

Wann, D.L. (1993). Aggression among highly identified spectators as a function of their need to maintain positive social identity. Journal of Sport and Social Issues, 17(2), 134-143.

Wann, D.L., \& Dolan, T.J. (1994). Spectators' evaluations of rival and fellow fans. The Psychological Record, 44, 351-358.

Wann, D.L., Carlson, J.D., \& Schrader, M.P. (1999). The impact of team identification on the hostile and instrumental verbal aggression of sport spectators. Journal of Social Behavior and Personality, 14(2), 279-286.

Wann, D.L., Schrader, M.P., \& Carlson, J.D. (2000). The verbal aggression of sport spectators: A comparison of hostile and instrumental motives. International Sports Journal, 4, 56-63.

Wann, D.L., Hunter, J.L., Ryan, J.A., \& Wright, L.A. (2001). The relationship between team identification and willingness of sports fans to consider illegally assisting their team. Social Behavior and Personality, 29(6), 531-536.
Wann, D.L., Melnick, M.J., Russell, G.W., \& Pease, D.G. (2001). Sport fans: The psychology and social impact of spectators. New York: Routledge. Wann, D.L., Culver, Z., Akanda, R., Daglar, M., Divitiis, C., \& Smith, A. (2005). The effects of team identification and game outcomes on willingness to consider anonymous acts of hostile aggression. Journal of Sport Behavior, 28(3), 282-294.

Wright, S.C. (2009). The next generation of collective action research. Journal of Social Issues, 65(4), 859-879.

Yoshida, M., Gordon, G., Heere, B., \& James, J.D. (2015). Fan community identification: An empirical examination of its outcomes in Japanese professional sport. Sport Marketing Quarterly, 24(2), 105-119.

Yin, R.K. (2009). Case study research: Design and methods. (4 ${ }^{\text {th }}$ Ed.) Thousand Oaks, CA: Sage.

Young, K. (2012). Sport, violence, and society. New York: Routledge. 


\section{Appendix}

Appendix A: Semi-structured Interview Protocol

1. Why did you choose to become a member of the [fan group name]?

2. Why did you decided to maintain your membership with the [fan group name]?

3. Any other reason for why you enjoy being a member of the [fan group name]?

4. How often do you attend the basketball games?

5. How organized is the [fan group name], do you have meetings or anything like that?

6. What do you believe is the purpose of the [fan group name]?

7. Have you ever been a member or are you currently a member of any other fan groups?

8. Can you describe the types of cheering you do at games?

9. Would you personally make any kinds of derogatory comments to the opposing team?

10. Are there any other members of the [fan group name] that are, make more mean-spirited remarks?

11. Is there any types of cheering that you do in the [fan group name] that you wouldn't do by yourself?

12. For some of those big games like [team name] where you have some of the students make some of the more abusive kind of remarks, what is your reaction to it? 
13. Do many of the [fan group name] members drink alcohol?

14. Do you notice much drinking that goes on before the game?

15. Do you feel that being a member of the [fan group name] has impacted the way you cheer at games? Is your cheering different now than how it was before?

16. Are you seated or standing during games?

17. Does your experience at those events differ from your experience in the [fan group name]? 